\title{
The use of pleurodesis for intractable pleural effusion due to congestive heart failure
}

\author{
D. DAVIDOFF \\ M.D. \\ Y. NAPARSTEK \\ M.D. \\ M. ELIAKIM \\ M.D. \\ Department of Medicine A, Hadassah University Hospital, 91120 Jerusalem, Israel
}

\begin{abstract}
Summary
Two patients in whom pleurodesis was used for intractable pleural effusion due to congestive heart failure are described. This procedure eliminated the pleural effusion but resulted in accumulation of fluid in other body compartments. Pleurodesis has a limited role in the treatment of intractable pleural transudates in congestive heart failure.
\end{abstract}

KEY WORDS: pleurodesis, pleural effusion heart failure.

\section{Introduction}

The use of pleurodesis is a widely accepted mode of treatment in recurrent malignant pleural effusion (Leff, Hopewell and Castello, 1978). However, pleurodesis in other conditions associated with intractable pleural transudates, e.g. nephrosis, cirrhosis or congestive heart failure is not often performed. The present $r \in$ port describes our experience with pleurodesis in 2 patients suffering from recurrent pleural effusion due to congestive heart failure.

\section{Case reports}

Case 1

A 71-year-old widow, suffered from essential hypertension and long-standing congestive heart failure, manifested by exertional and nocturnal dyspnoea, orthopnoea, right pleural effusion and mild peripheral oedema. In 1980, the patient was admitted to the hospital 12 times because of dyspnoea. She was treated on each occasion by pleurocentesis, and 2-3 litres of transudate were evacuated from the right pleural space. In addition, she was on maintenance doses of digoxin, frusemide, spironolactone, isosorbide dinitrate and hydralazine. In January 1981, 6.5 litres were evacuated in the course of 10 days. On day $11,1.0 \mathrm{~g}$ tetracycline was inserted into the right pleural space. This was followed by the appearance of mild pleuritic pain. A week later, the oedema in the legs increased markedly and a small amount of pleural fluid appeared on the left for the first time. The pleural effusion on the right side did not accumulate again, but she continued to suffer from dyspnoea, orthopnoea, pitting oedema and weight gain. The fluid in the left pleural cavity persisted and was intractable to treatment. In July 1981, the patient died after a cerebrovascular acc dent.

Comment. The administration of $1.0 \mathrm{~g}$ of tetracycline into the right pleural space resulted in adhesions and cessation of accumulation of fluid. However, this was followed by the appearance of left pleural effusion and aggravation of the signs of right heart failure. The dyspnoea, which was the patient's main complaint, did not improve.

\section{Case 2}

A 60-year-old male suffered from myocardial infarction in 1978 and 1979. In June 1979, the patient was hospitalized on 2 occasions because of severe and progressive dyspnoea and a large right pleural effusion. He underwent pleurocentesis, but the signs 9 of congestive failure progressed in spite of treatment with digitalis, diuretics and the removal of 1-1.5 litres of pleural transudate every week.

In November 1979, $200 \mathrm{mg}$ quinacrine hydrochloride (Atabrine) were injected into the right pleural space. This was followed by pleuritic pain and a $\mathrm{N}$ febrile reaction lasting 6 days with the temperature going up to $38^{\circ} \mathrm{C}$. During the following 18 months, he 0 was hospitalized on many occasions because of $\frac{}{\Phi}$ severe dyspnoea and a left-sided pleural effusion, $\stackrel{\mathcal{O}}{\rightarrow}$ necessitating repeated pleurocenteses. The effusion $T$ on the right side did not recur.

Comment. The administration of quinacrine hy- 
drochloride into the right pleural space resulted in adhesions and cessation of fluid accumulation. However, a large pleural effusion appeared on the left side and repeated pleurocentesis was necessary for its treatment.

\section{Discussion}

In a study of 436 patients with pleural effusion Leuallen and Carr (1955) found that in about one half of the cases $(52.5 \%)$ the effusion was of malignant origin. Ten percent were due to congestive heart failure, $8.3 \%$ to infections, while the remainder were due to rare or indeterminate causes. The classical differentiation between a transudate and an exudate is still of major diagnostic and therapeutic importance. The main causes of transudates are congestive heart failure, cirrhosis, nephrosis and hypoproteinemia of other causes. It is widely accepted that if the fluid is clearly a transudate 'one need not worry about therapeutic measures directed at the pleura' but rather treat the basic disease (Light and Macgregor, 1972).

Nevertheless, physicians are occasionally confronted with patients in whom the pleural transudate presents as a local problem, causing a great deal of discomfort and restriction and proving to be intractable to systemic treatment.

Spicer and Fisher (1969) report a patient with congestive heart failure and a large pleural effusion resistant to conventional therapy, who underwent pleurodesis with silver nitrate, resulting in the disappearance of the effusion. In 1974, Jenkins and Shelp reported a patient with recurrent pleural effusion, resistant to diuretic therapy and haemodialysis due to rapidly progressive renal failure and nephrotic syndrome. Eighteen months after the intrapleural injection of tetracycline, there was no recurrence of pleural fluid. Falchuk and Jacoby (1977) reported 2 additional cases of pleural effusion complicating liver cirrhosis, again eliminated only after pleurodesis. However, although the pleural effusion disappeared, the ascites remained, and in one case, became worse.

The appearance of effusion in congestive heart failure is a consequence of imbalance between increased fluid diffusion from the parietal pleura and decreased reabsorption from the visceral sheath. This is a result of increased systemic capillary pressure on one hand and elevated pulmonary capillary pressure on the other. Both factors can obviously be treated by diuretics, digitalis and afterload reductants. Our experience with the 2 cases presented above indicates that blocking one pleural space results in pleural effusion on the other side and deterioration of the manifestations of congestion in other available compartments. Therefore, the role of pleurodesis in the treatment of congestive heart failure is doubtful and this procedure should be reserved for patients in whom every other conservative measure has failed, taking into account the possible morbidity from recurrent pleurocenteses on one hand and the risk of continued accumulation of fluid in other body spaces on the other.

A variety of agents have been used to achieve pleural symphysis, but tetracycline seems to be the simplest and most convenient one, causing a low morbidity and no systemic effects. Mild pleuritic pain is the most common and relatively easily tolerated side effect (Robinson and Bolooki, 1972).

\section{References}

FALCHUK, K.R. \& JACOBY, I. (1977) Tetracycline-induced pleural symphysis for recurrent hydrothorax complicating cirrhosis. Gastroenterology, 72, 319.

JENKINS, P.G. \& SHELP, W.D. (1974) Recurrent pleural transudate in the nephrotic syndrome. Journal of the American Medical Association, 230, 287.

Leff, A., Hopewell, P.C. \& Castello, J. (1978) Pleural effusion from malignancy. American Journal of Internal Medicine, 88, 532.

Leuallen, E.C. \& CARR, D.J. (1955) Pleural effusion: A statistical study of 436 patients. New England Journal of Medicine, 252, 79.

Light, R.W. \& MACGREgoR, M.I. (1972) Pleural effusion: The diagnostic separation of transudates and exudates. Annals of Internal Medicine, 77, 507.

RoBINSON, R.U. \& BoLOOKI, H. (1972) Intrapleural tetracycline for control of malignant pleural effusions: A preliminary report. Southern Medical Journal, 65, 847.

SPICER, A.J. \& FISHER, J.A. (1969) Recurring pleural effusion in congestive heart failure treated by pleurodesis. Journal of the Irish Medical Association, 62, 177.

(Accepted 18 August 1982) 